\title{
EGAH editorial- to mark the 50th anniversary of SEGH
}

\author{
Brian E. Davies • Michael J. Watts • Sherestha Saini • Gillian Gibson • \\ Anthea Brown $\cdot$ Ming Hung Wong
}

Published online: 12 April 2021

(C) The Author(s), under exclusive licence to Springer Nature B.V. part of Springer Nature 2021, corrected publication 2021

\section{SEGH: Fifty years on and counting}

As the Society for Environmental Geochemistry and Health (SEGH) reaches the year in which it celebrates its fiftieth birthday, our associated journal could not allow this to pass unnoticed. Throughout the year there will be a series of short papers on a variety of subjects, which have been written in a collaborative fashion, between the geologists and health professionals; between Fellows and Early Career Researchers; between academics and business. We hope you will find them informative and useful. Before that, however, it is a good time to take stock of the Society, to consider its journey so far, and its aspirations for the future. We hope that you will agree with the way in which it is hoped that the Society will develop and that you will join with us in ensuring that in another fifty

\section{B. E. Davies}

Clemson University Emeritus College, 511 Westinghouse

Rd., Pendleton, SC 29670, USA

e-mail: ewartdavies@gmail.com

\section{J. Watts}

Inorganic Geochemistry, Centre for Environmental

Geochemistry, British Geological Survey, Nottingham, UK

e-mail: mwatts@bgs.ac.uk

\section{S. Saini}

Springer Nature, One New York Plaza, Suite 4600,

New York, NY 10004-1562, USA

e-mail: sherestha.saini@springer.com years there will be a subsequent piece celebrating one hundred years of SEGH.

Since the late nineteenth century, improvements in human health have been dramatic for diseases caused by pathogens. Mass vaccinations together with antibiotics and other drugs mean we no longer need to fear the scourge of bubonic plague or watch as the poliomyelitis virus changes healthy children into wheelchair cripples. However, it is said 'you are what you eat' and improvements in public health and environmental sanitation have brought into sharper focus the way the geochemical environment might also affect health through the composition of food, air and drinking water. An environmental contribution is known or suspected for many diseases such as cancers or heart problems. Consequences of exposure to the geosphere comprise the rationale of SEGH.

G. Gibson

Gibson Consulting and Training, Tarporley,

Cheshire, UK

e-mail: gillian@gbgibson.com

\section{A. Brown \\ British Geological Survey, Nottingham, UK \\ e-mail: seghmembership@gmail.com}

M. H. Wong $(\bowtie)$

School of Environmental Science and Engineering,

Southern University of Science and Technology,

Shenzhen, China

e-mail: wongmh@sustech.edu.cn 
In 1967, the late Dr. Delbert Hemphill had launched a long and successful series of annual conferences, 'Trace Substances in Environmental Health' (TSEH), held in the University of Columbia, Missouri. In 1969, the (US) National Research Academy approved a subcommittee on the 'Geochemical Environment in Relation to Health and Disease' (see preface in Cannon and Hopps (1974)). At the fourth TSEH meeting held in 1970, the 'Society for Environmental Geochemistry and Health' (SEGH) was instituted as a body for researchers in the chemical environment and health to meet, discuss and often collaborate. The founding member group comprised H.C. Hopps, H.L. Cannon (Co-Chairs), A. Agnew, W.D. Binns, J.F. Hodgson, E. Ingerson, W.W. Rubey, H.V. Warren, C. Marienfeld and W. Mertz. SEGH was subsequently incorporated as a 'non-profit' in the State of Missouri, USA. Drs. Bobby G. Wixson and (the late) Nord Gale undertook the legal responsibilities of reporting annually to the state until August of 2018 when diminishing US membership forced de-incorporation. SEGH continued to hold its annual meetings in conjunction with TSEH until 1993 when the conference series ended. After that, conferences in the USA became less frequent.

Originally, SEGH was perceived as an American society but international delegates, especially those from the UK, became regular participants in TSEH. In 1982, the SEGH board approved the institution of a European group by B.E. Davies to serve the interests of members who could not attend TSEH meetings. The first of a continuing series of annual meetings was organised by Davies in Birmingham in 1982. At the third in 1984, sufficient interest and enthusiasm had developed for others to take on organising future meetings first in the UK and later in Europe. Conferences play a special role in science: beyond formal presentations and poster displays, there is the opportunity for networking in conference receptions, informal social events and field excursions. SEGH has been very effective in promoting collaboration by members both nationally and internationally as a consequence of its conferences.

The success of European local meetings became recognised and emulated. At several SEGH conferences, colleagues from the Asia-Pacific area indicated they would welcome the opportunity to participate in a local SEGH section. SEGH approved the formation of the Asia-Pacific Section of the Society in 1998 in conjunction with the First Asia-Pacific Symposium on Environmental Geochemistry in Hong Kong, November 1998. Now, conferences outside Europe and America have become a regular feature of the SEGH calendar.

Over fifty years, SEGH has recognised and reacted to many environmental concerns. Tetraethyl lead was extensively used as an anti-knock agent in petrol during the twentieth century. In addition, there had been a widespread problem of lead-based paints used in millions of homes built before the 1970s. Lead pollution was shown to damage the mental development of children, and the source was ingestion of contaminated soil outside (pica) and contaminated floor dust inside the home by toddlers. SEGH responded to the problem by acquiring funds to form a task force to establish guidelines for lead in soil. The subsequent report 'Lead in Soil' contained a phased action plan to evaluate the potential health effect of a given soil lead concentration (Wixson \& Davies, 1993). Its recommendations influenced statutory regulations in both the US and the UK. The report has been reprinted (2018) by CRC Press, in its CRC Revivals series. Growing concern about arsenic in drinking water led in 1991 to a second SEGH task force. It was chaired by Drs. Willard Chappell and Charles Abernathy and there were dedicated conferences in 1993, 1995 and 2000 with a final report edited by Chappell et al. (2003). This task force strongly influenced subsequent US drinking water regulations.

Regular SEGH conferences with dedicated special sessions have brought together researchers in most of the other substances of environmental concern over fifty years. EGAH has published SEGH conference proceedings, as papers or extended abstracts, and their titles bear testimony to the success of SEGH in highlighting those concerns over the years. Originally SEGH members received a regular newsletter, Interface, which contained both society news and notes on members' research. Now SEGH has its own website in succession to Interface to support its activities. Members are able to access EGAH with their own password.

The remarkable success of a small society in continuing and prospering over fifty years is a tribute to its members' enthusiasm and its officers' dedication. It is unfortunately not practicable to list all who have served as Board members, Treasurers and Secretaries since 1971. However, any institution 
depends on the qualities of its leaders for its success, and it is appropriate to list those who have served as President since 1971: D.D. Hemphill (USA); P. Newberne (USA); L. Hurley (USA); J. Freedman (USA); G.K. Davis (USA); I. Smith (USA); E.E. Angino (USA); H.C. Hopps (USA); E. Jenne (USA); W.J. Pories (USA); B.G. Wixson (USA); A.L. Page (USA); C. Marienfeld (USA); I. Thornton (UK); E. Ohanian (USA); B.E. Davies (UK); N.L. Gale (USA); R. Cothern (USA); B.T. Kagey (USA); R. Fuge (UK); J. Fricke (USA); J. Farmer (UK); A. Hunt (USA); J. Carter (UK); X.D. Li (China - Hong Kong); A. Hursthouse (UK); C.S. Zhang (Ireland); (currently) M. Watts (UK).

We salute our past Presidents and all the many other officers of SEGH who, over fifty years, have worked to make SEGH durable and successful. We look forward to the years to come knowing our enthusiasm and dedication will make SEGH a continuing academic force.

Building on that illustrious past, the society continues to push at the boundaries of knowledge and understanding of the interface between geology and health.

The challenges of sustainable development are ever more present in the 50th anniversary year of SEGH and the skills of the SEGH member are well placed to make meaningful contributions to the environment, society and well-being, often framed as policy/pathways to impact or within the United Nations Sustainable Development Goals (SDGs). There have been previous commentary articles from SEGH on the evolution of the society since the 1970s (Wixson and Davies 2019), as referenced above, and in recent years (Watts et al., 2020a). Throughout the years, SEGH has evolved to meet the changing environmental and health challenges, alongside competition in the crowded market for learned societies and rapid changes in regional growth both economically and scientifically, as seen in Asia and Africa, presenting greater opportunities for diversity within societies such as SEGH.

SEGH was slow to utilise information technology, but in 2011 implemented a functional website to exchange information between members, access the EGAH journal and make online payments. Importantly, the website transformed the strategic planning of the society using the analytics behind the functionality of the website, by being able to track the changes in how the website was accessed and from which countries, evidencing the already enormous interest from Asia, but also the growing potential in Africa. Interestingly, and unfortunately, interaction from the Americas declined during the 2010s to almost nothing, whilst engagement remained stable in Europe and expanded rapidly from within Asia and also in particular from Africa (Fig. 1), with the first African conference held in Victoria Falls, Zambia (Watts et al. 2018).

A new African section is represented on the international board of SEGH. Both of these regions have presented a new dynamism to SEGH, particularly for multidisciplinary research activities. It is anticipated that the Americas will be revived via growing links to Central America and Canada through recent and future initiatives planned for 2021 onwards. The experience in Africa provides valuable lessons for the rebuilding of the Americas section, with emphasis on early career researchers ECRs and regular and more informal use of communications platforms between senior and junior scientists to provide a more equitable membership profile.
Fig. 1 SEGH Members regional guide 2015-2020

\section{SEGH Members regional spread 2015 - 2020}
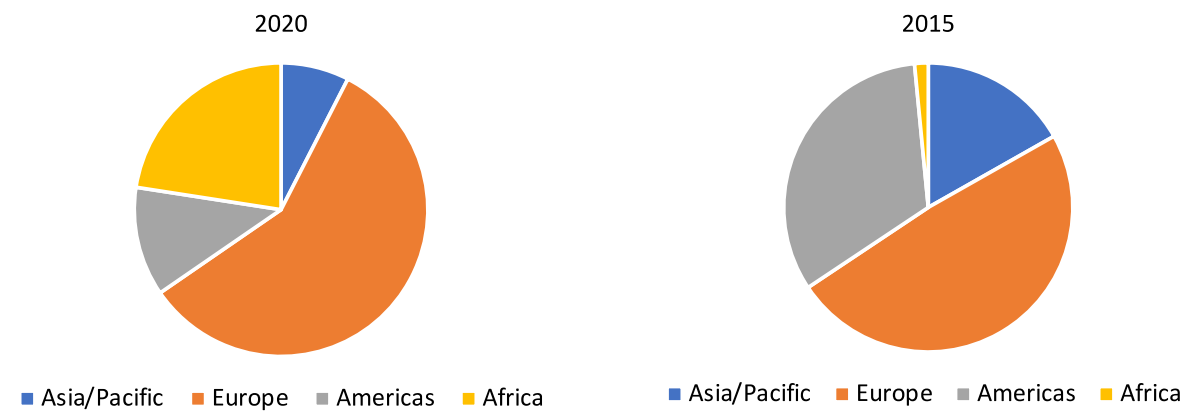
The SEGH website underwent another relaunch in 2020 to bring it up to date with greater functionality. There are now 'member areas' to access presentations, learning materials and also specified functions for ECRs, with the flexibility to adapt the website in the future.

We were to see the advent of two rather than one international conferences in 2020, in Kenya and China, alongside smaller regional meetings. However, the COVID-19 crisis rippled across the world causing physical meetings to be postponed. SEGH responded quickly to the situation by delivering an online conference via a Zoom webinar in June 2020-SEGH Live-which had 100 + registrants from 35 countries and $\sim 40$ presentations (Watts et al. 2020b). Owing to demand for this format in a world of reduced travel, a regional online meeting for ECRs was held for Nigerian and Kenyan participants later in 2020 and a training module for ECRs around the world via a webinar in November. An SEGH 'Live 2' event followed in February 2021, in addition to an Americas-focused online meeting later in 2021. It is likely that this format of meeting will continue even when physical travel resumes. It provided an equitable point of access for members to present their work and listen to other delegates from around the world for the cost of the SEGH membership, as well as reducing the carbon footprint of our meetings: a responsible position to take given the nature and knowledge of our society! This format will need to innovate to fill the gap in social interaction usually experienced at physical conferences. The latter will likely evolve as hybrid meetings with physical delegates joined by online contributors able to access streamed presentations, enabling a wider and growing equitable approach for contributors whatever their personal resources.

In 2020, we also started to see other initiatives grow in confidence, with a formal Fellowship programme for SEGH members of notable contribution to the society and SEGH community. In addition, the formalisation of an ECR group has matured since 2020 with a commentary article in EGAH, articulating their aspirations as a group for the future of SEGH activities (Humphrey et al. 2020), with, hopefully, evidence of a growing confidence to provide some leadership for their own mentorship programme and ECR activities. This group is ultimately the future of SEGH membership and the international board and needs to be nurtured.
In 2019, the international board presented to the membership via the website and online a summary of future aspirations (Watts et al. 2020a) for which we have had mixed success so far. Highlights include:

- Improve the engagement with epidemiologists and health practitioners and translation of research into policy-whilst we have increased members in these fields three- to fourfold via increased presence at conferences, further effort is still required, given the low starting point. Further work is required to evidence how members are translating research to policy and how members are connecting with each other to do so.

- Continue to increase regional membership hubs to grow geographical diversity of membership - the trend is encouraging, with notable successes in Africa, particularly with active hubs in Nigeria and Kenya driving activities for Africa.

- Grow the Early Career Researcher programme for succession management of SEGH and stay on trend with the latest research-the ECR programme is maturing into a coherent group that has been communicating with ECRs leading discussion for future activities and online training events delivered outside of the usual conference programme. Further consolidation is required, with further responsibility to be taken on by the ECR group to maximise their benefit from and to the SEGH community.

- Evolve the relevance of SEGH goals to include the United Nations Sustainable Development Goals to reinforce relevance to policy impact-whilst the wider SEGH community is probably making good progress on this point, SEGH needs to evidence its role in SDGs through an evaluation and monitoring process. The planned $50^{\text {th }}$ anniversary initiative for EGAH will comprise a collection of commentary and review articles which will in part raise awareness of the SEGH community relevance to SDGs and translation of research to policy impact.

Overall, the increasing pace of change to evolve and remain relevant as a society requires SEGH to redouble efforts on our aspirations and to better evidence the community's contribution to translating research into policy and relevance to the United Nations SDGs with greater geographic membership and opportunities provided for interaction can be 
confident in contributing to the SDG17-partnership for the goals.

Much as the focus and membership of SEGH have evolved over the years, so too has the nature, scale and scope of the Journal.

The growing success of SEGH in both Europe and the US had revealed a need for a journal to publish in one place papers relevant to environmental geochemistry and health. In 1985, an international symposium on geochemistry and health (organised by Professor Iain Thornton, President of SEGH) in London, UK coincidentally brought together active members of SEGH and Dr Peter Farago, publisher of 'Minerals and the Environment,' a journal which focused on mining, pollution and remediation. It was proposed to rebadge the journal as 'Environmental Geochemistry and Health' (EGAH) with a much wider brief and create a close partnership with SEGH. Professor Brian Davies was invited to be the new Editor-in-Chief: he had been a member of SEGH since 1970 and long active in the leadership of the society. For operational reasons EGAH continued as Volume 7, No. 1.

In an editorial prefacing the first issue, Davies wrote: 'there remains a strong possibility that local environment may influence human health as it certainly influences animal health'. The purpose of the journal was to offer a platform for papers in the broad field of environmental geochemistry and health and to support the activities of SEGH, especially its conferences. EGAH now publishes original research papers, short communications and review papers in both regular and special issues, across the broad field of environmental geochemistry. Papers link the natural or disturbed chemical composition of the earth's surface with the health of its biota, which includes microorganisms, plants, animals and human beings.

By 1988, EGAH was becoming sufficiently established in its new persona that the subtitle 'Minerals and the Environment' was dropped from the mast head. In 1995 EGAH passed to a new publisher (Chapman \& Hall, London) with the immediate benefit of providing the editor with the aid of a professional production staff to take over purely administrative details. This was a welcome change from the voluntary work responsible for EGAH production prior to printing. As the journal grew, relying on volunteers, dedicated but often with other priorities, had unfortunately slowed manuscript turn around and hence hindered its development. In 1999, ownership passed to Kluwer Academic Publishers of Dordrecht (the Netherlands).

When EGAH was launched, it was essentially desktop publishing exercise for which an A4 format was most suitable. A new smaller format was adopted from 1999 along with a redesign of the cover, which brought us into line with other journals.

This journal, together with SEGH, has identified and reacted to many emerging environmental geochemistry topics. At a time when there was belief that aluminium might play an important role in causing Alzheimer's disease Volume 12 of 1990 was a special issue devoted to the proceedings of a workshop in Oslo, Norway summarising what was then known of aluminium and health. In 1991, Volume 13 printed selected papers at a SEGH (Europe) conference in Bath, England devoted to environmental radioactivity. In 1992, we were prescient for we devoted a whole issue (Volume 14-2) to environmental arsenic. In 1993, the world became aware of the arsenic tragedy in Bangladesh where tube wells installed with the laudable intent of providing clean water were drawing from an arsenic rich aquifer. For long, it seemed as though environmental geochemistry was the concern of only the western industrialised nations but 1996 Volume 18-3 published papers on environmental geochemistry in the Caribbean, especially Jamaica. In 2002, Volume 24-2 carried the Transactions of the First Workshop of the East and Southern Africa Association of Medical Geology. Over the years, the geographic spread of authors has become more widespread and EGAH truly international.

In 2002, Davies retired from his then university (Clemson, USA) and handed editorial responsibilities over to Professor Ming Hung Wong, its present Editorin-Chief, as a successful and established journal. Over the early years of development, EGAH owed much to members of SEGH who submitted their research as papers to what was still an emerging journal. Davies remains grateful to all his SEGH colleagues, paper reviewers, publishers and to several university departments (Aberystwyth, Bradford, Clemson) and many graduate students for support during his tenure as Editor-in-Chief. The continuing development and success of EGAH since 2002 under its present Editor-in-Chief has repaid the faith of all those early supporters (Wixson \& Davies, 1993). 
During the time of the various Editors-in-Chief, the process of preparation of the Journal has undergone many iterations and innovations. When EGAH was launched, word-processing was in its infancy (Wordstar and 'daisy wheel' printers with edge-perforated fan fold paper were cutting-edge technology) and papers were submitted as typescript in three copies. In 1956 Dr. Eugene Garfield had founded The Institute for Scientific Information ${ }^{\mathrm{TM}}$ and pioneered concepts of a citation index as well as issuing 'Current Contents'.

Google Scholar lay far in the future. EGAH now operates in a very different publishing climate and benefits from the new technology. Manuscript submission and handling is digital and over the Internet and the paper offprints of yesteryear have become downloaded digital facsimile copies (.pdf files).

Professor Wong assumed responsibilities as the new Editor-in-Chief of the journal in 2003 and under his leadership full advantage has been taken of new technology. Email alerting services increase the visibility of journals and their papers and hence the attractiveness of a particular journal for a researcher. EGAH is proving attractive. Since 2017, EGAH has more than doubled article publication (from 112 in 2017 to 288 in 2020). The journal went from publishing quarterly issues from 1979 to 2004 (Volumes 1-26), bi-monthly issues from 2005 to 2019 (Volumes 27-41), and in response to the increasing output, monthly issues beginning in 2020 .

Internet visibility is international and paper submission is international. Submissions to the journal in 2020 have come from authors based in 78 countries truly representing interest from an international author base. The majority of submitters were from Asian countries like China and India followed by those from Iran, Russia, and Nigeria. Article submissions from Spain, Italy, Poland, and the UK have also increased over recent years. Contributions are accepted from a wide geographical range as well (namely China, India, Korea, the USA, Russia, Iran and the UK) to ensure a broad representation of geochemistry and health issues across the globe.

Citation metrics are an important measure of a journal's reputation and researchers seek to publish in journals which are read and frequently cited. We are pleased to announce that the journal downloads calculated from Springerlink accesses increased 15\% from 193,969 downloads in 2019 to 293,521 downloads in 2020. The $\mathrm{h}-5$ index of the journal increased from 24 in 2015 to 37 in 2020 and CiteScore calculated from data in the Scopus database increased from 3.5 in 2015 to 5.2 in 2020.

EGAH's 2-year impact factor was 3.472 and 5-year impact factor was 3.662 as released in the Clarivate Analytics Journal Citation Reports (JCR) based on 2019 data. Both values are the highest recorded for the journal so far. The journal is now ranked in the top $25 \%$ of journals (Q1) in the subject categories of Water Resources (14/94) and Public, Environmental and Occupational Health (39/193). Additionally, it is ranked in Q2 in the categories of Environmental Sciences (83/265) and Environmental Engineering (22/53). Based on Altmetric data, EGAH has received 2,218 mentions by readers and authors in its lifetime according to Altmetrics, with a significant increase in discussions and mentions (95 in 2015 to 711 and counting in 2020), especially on social media (e.g., Twitter) and specialised news sources.

In 2021, we plan on setting up an editorial board of early-career researchers (ECRs) comprising $\mathrm{PhD}$ and postdoctoral students drawn from the SEGH membership from diverse backgrounds who would be able to learn about the peer-review process by becoming a reviewer themselves. They would also receive feedback from an associate editor who would serve as their mentor and provide constructive feedback on the ECR's review comments. More to come on this initiative soon.

We would like to thank sincerely all the advisory board members, associate editors and special issue guest editors for their hard work and commitment. Without their support, the journal would not be as successful as it is today.

The authors consider that this article paints a picture of a relevant, forward looking, dynamic organisation, prepared to embrace appropriate technology where possible, and for which geographical borders are irrelevant. Collaboration is actively sought across continents and between disciplines. Novel concerns are considered openly and researched extensively. The Society welcomes new members from all disciplines and locations. We hope that this article has whet your appetite for more engagement with the society, and that you will become a member, if not already. 


\section{References}

Cannon, H. C. H. (1974). Geochemistry and the Environment: Volume I: The Relation of Selected Trace Elements to Health and Disease. The National Academies Press.

Cannon, H. L., \& Hopps, H. C. (Eds.). (1974). Geochemistry and the Environment, I: The Relation of Selected Trace Elements to Health of Diseases. The National Academies Press.

Chappell, W. R., Abernathy, C. O., Calderon, R. L., \& Thomas, D. J. (Eds.). (2003). Arsenic Exposure and Health Effects $V$ (Arsenic Exposure and Health Effects Series). Elsevier Science.

Davies, B. E. (1985). Airs, waters and places. Environmental Geochemistry and Health, 7, 1.

Humphrey, O. S., Middleton, D. R. S., Ahmad, S. et al. (2020). The society for environmental geochemistry and health (SEGH): building for the future of early career researchers. Environ Geochem Health. https://doi.org/10.1007/s10653020-00620-4.

Watts, M. J., Maseka, K. K., Sakala, G., Mutondo, M. (2018). SEGH 2018 Vic Falls: Geochemistry for sustainable development, July 17, 2018 http://www.segh.net/articles/ segh_2018_vic\%20Falls_geochemistry_for_sustainable_ development/

Watts, M. J., An, T. C., Argyraki, A., et al. (2020a). The society for environmental geochemistry and health (SEGH): building for the future. Environmental Geochemistry and Health, 42, 343-347. https://doi.org/10.1007/s10653-01900381-9

Watts, M. J., Humphrey, O. S., \& Middleton, D. R. S. (2020b). SEGH live and beyond. Environ Geochem Health. https:// doi.org/10.1007/s10653-020-00722-z.

Wixson, B. G., \& Davies, B. E. (1993). Lead in Soil. Recommended Guidelines. Science Reviews Ltd.

Wixson, B. G., \& Davies, B. E. (2019). The society for environmental geochemistry and health (SEGH): A retrospect. Environmental Geochemistry and Health, 1, 2-3. https:// doi.org/10.1007/s10653-019-00262-1.

Publisher's Note Springer Nature remains neutral with regard to jurisdictional claims in published maps and institutional affiliations. 